\title{
URGENSI SISTEM PENJAMINAN MUTU INTERNAL TERHADAP PENINGKATAN MUTU PERGURUAN TINGGI
}

Oleh

Muh. Fitrah, Ruslan, Hendra

Institut Agama Islam (IAI) Muhammadiyah Bima

fitrahmath@gmail.com, ruslanamarizqi@gmail.com, hendrasilabi@gmail.com

Diterima 8 Desember 2017, direvisi 28 Januari 2018, diterbitkan 28 Pebruari 2018

\begin{abstract}
One of the effects of globalization is the increase of the opportunity of work but this is accompanied by the strict competition in getting job caused by globalization so the implementation system of university should continually be able to anticipate those dynamic changes that the alumnus has the high competition level. This condition underlines the urgency of system implementation of internal quality guarantee. System implementation of internal quality guarantee was made as the basis control management of the high education quality with national standard. The process of system implementation of internal quality guarantee was not far from quality, target of education implementation quality, and all documentations of quality that mus be socialized elements of academic and institution leader to implement optimally because the important values of effort from system of internal quality guarantee if the discovery gotten, was continued by planning and application of programs for future fixes. There were some crucial urgencies gotten by university in evaluation that was done by system of internal quality guarantee, university should; 1) able to identify power and weakness as the basis of arrangement of continue plan of development. 1) able to learn the opportunity to develop the quality of education, score the success of development effort, and do adaptation of programs; 3) able to know the level of performance success based on Standard, and 4) able to supply the valid report to holder of interest about progress and result-raised.
\end{abstract}

Keywords; urgency, System of internal quality guarantee 


\section{PENDAHULUAN}

Penjaminan mutu perguruan tinggi di Indonesia secara formal baru dimulai tahun 2003 yaitu terbitnya pedoman penjaminan mutu perguruan tinggi.Faktor yang paling memacu gerakan penjaminan mutu adalah keharusan perguruan tinggi untuk menyelenggarakan penjaminan mutu, di samping tuntutan akuntabilitas dan kualifikasi lulusan (Olssen, 2004: 194). Adina (2007: 2) menegaskan bahwa penjaminan mutu di perguruan tinggi secara keseluruhan sangat penting sebab sasaran pendidikan bukan hanya untuk akademik semata, akantetapi keseluruhan pribadi. Namun dalam sisi lain kehadirannya dapat didasari alasan lain seperti ketidakpuasan dari tenaga kependidikan dan mahasiswa serta desakan karena terbatasnya danadan paling penting ialah tuntutan untuk melakukan pertanggung jawaban terhadap kelembagaan (Tsui, 2002: 3).Lebih lanjut Achmad Anwar Abidin (2017: 87) mutu pendidikan tinggi di Indonesia masih kalah dibanding Negaranegara tetangga kita di kawasan Asia Tenggara. Itulah sebabnya upaya peningkatan mutu pendidikan menjadi perhatian para pakar pendidikan dan pemerintah untuk mewujudkannya.

Di era kehidupan global yang penuh persaingan saat ini, pendidikan tinggi di Indonesia menghadapi tantangan yang sangat penting untuk terus meningkatkan mutu kompetitif tingkat daerah, nasional, maupun internasional. Sufyarma (2004: 161) mengemukakan bahwa era globalisasi adalah era persaingan mutu.Maka perguruan tinggi di era globalisasi harus berbasis pada mutu, bagaimana perguruan tinggi dalam kegiatan jasa pendidikan maupun pengembangan sumber daya manusia yang memiliki keunggulan.

Perguruan tinggididorong untuk mengejar standar mutuyang lebih baik karena inovasi teknologidan perilaku pasar pragmatisrasional. Dalam manajemen sumber daya manusia disebutkan bahwasetiap orang dalam sebuah organisasi berhak mengembangkan dirinya dalam rangka peningkatan dan kemajuan kariernya (Cecep Alba, 2011: 1188).Mutu dalam lingkup pendidikan di perguruan tinggi memiliki arti bahwa fungsi, tujuan, serta standar yang ditentukan dan dijalankan di lingkup perguruan tinggi telah sesuai, memenuhi syarat, harapan, dan kepuasan stakeholder. Perguruan tinggi yang tidak berbenah akan ditinggalkan oleh stakeholders (Muhammad Khoiri, 2010: 208).

Mutu lulusan berkaitan dengan ciri khas yang ditentukan oleh perguruan tinggi serta menunjukkan kesiapan lulusan untuk terjun dan berkarya langsung di masyarakat dan dunia kerja sebagaimana diharapkan oleh pelanggan dan stakeholders. Senada dengan penjelasan dari Dikti (2003: 8) bahwa perlu dikemukakan karena penilaian stakeholders senantiasa berkembang, maka penjaminan mutu juga harus selalu disesuaikan pada perkembangan itu secara berkelanjutan.Berdasarkan hasil penelitian Reddy Siram (2015: 54) mengungkap bahwa perguruan tinggi perlu memberikan perhatian terhadap manajemen penjaminan mutu lulusan karena masih banyak lulusan yang terserap di dunia kerja namun tidak sesuai dengan kualifikasi dan latar belakang pendidikan yang ditempuhnya.

Penjaminan mutu merupakan suatu proses sistematis dan berkelanjutan yang bertujuan menghasilkan, meningkatkan, dan mempertahankan mutu suatu institusi sehingga kualitasnya terjamin dan diakui masyarakat. Penjaminan mutu di perguruan tinggi dilakukan untuk mengukurseberapa efektif kebijakan akademik yang diterapkan dan seberapa tinggi mutu lulusan yang dihasilkannya, selain untuk meningkatkan daya saing di antara Perguruan Tinggi, baik di dalam maupun di luar negeri.Menurut Kementrian Pendidikan Nasional (2010: 16) penjaminan mutu perguruan tinggi adalah proses perencanaan, pemenuhan, pengendalian, dan pengembangan standar pendidikan tinggi secara konsisten, 
sehingga pemangku kepentingan internal dan eksternal perguruan tinggi dapat memperoleh kepuasan atas kinerja dan keluaran perguruan tinggi (Ahmad Sulaiman \& Udik Budi Wibowo, 2016: 28).Perguruan tinggi melakukan upaya peningkatan mutu pendidikan tinggi diantaranya melalui implementasi sistem penjaminan mutu internal (Kadek Hengki Primayana, 2015: 7).

Menurut Pasal 53 dan Pasal 52 ayat (4) UU Dikti, SPM Dikti terdiri atas sistem penjaminan mutu internal (SPMI) dan sistem penjaminan mutu eksternal (SPME) (Ristekdikti, 2010: 8; 2016: 7). Kegiatan penjaminan mutu perguruan tinggi dilaksanakan dalam sebuah sistem yang disebut sistem penjaminan mutu internal perguruan tinggi yang bertujuan untuk menjamin mutu pendidikan tinggi yang diselenggarakan oleh setiap PT, melalui penyelenggaraan Tridharma Perguruan Tinggi, dalam rangka mewujudkan visi serta memenuhi kebutuhan pemangku kepentingan internal dan eksternal perguruan tinggi (Debby Willar, 2015: 193).

SPMI adalah kegiatan sistemik penjaminan mutu pendidikan tinggi oleh setiap perguruan tinggi secara mandiri untuk mengendalikan dan meningkatkan penyelenggaraan pendidikan tinggi secara berencana dan berkelanjutan (Ristekdikti, 2016: 21).Menurut Ahmad Sulaiman \& Udik Budi Wibowo (2016: 28) bahwa SPMI di suatu perguruan tinggi merupakan kegiatan mandiri dari perguruan tinggi yang bersangkutan sehingga proses tersebut dirancang, dijalankan, dan dikendalikan sendiri oleh perguruan tinggi yang bersangkutan tanpa campur tangan dari pemerintah. SPMI Perguruan Tinggi dijalankan melalui beberapa tahapan yakni proses pelaksanaan penjaminan mutu internal, evaluasi diri, audit internal, serta tindakan koreksi. Hal ini harus didukung dengan komitmen dan kinerja pelaku proses pendidikan tinggi, serta pengorganisasian lembaga penjaminan mutu, sehingga proses kendali mutu dapat berjalan dengan efektif disertai dengan hasil evaluasi mutu yang positif.
Mutu pendidikan di perguruan tinggi hendaknya merupakan pencapaian dari visi, misi, serta tujuan perguruan tinggi yang disesuaikan dengan kompetensi lulusan yang diharapkan, kebijakan mutu dan standar mutu akademik yang telah ditetapkan, serta mencakup aspek input, proses dan output yang didasarkan pada nilai profesionalitas melalui penyelenggaraan Tri Dharma Perguruan Tinggi. Lembaga penjamin mutu sebagai pelaku SPMI harus memastikan bahwa SPMI diterapkan dengan tujuan untuk menjamin mutu pendidikan melalui penyelenggaraan Tri Dharma Perguruan Tinggi.

SPMI juga berperan penting untuk menjawab berbagai masalah terkait pendidikan serta sebagai alat untuk menganalisis tantangan pendidikan perguruan tinggi.Oleh karena itu, mengacu pada konsep yang diuraiakan diatas, maka sesungguhnya tulisan ini akandifokuskan pembahasannya pada urgensi SPMI terhadap peningkatan mutu perguruan tinggi.

\section{PEMBAHASAN}

\subsection{Mutu Perguruan Tinggi}

Berbicara tentang mutu bukan persoalan yang sederhana dan mudah, sebab mutu sifatnya abstrak.Tjiptono \& Diana (1995: 2) menjelaskan konsep mutu itu sendiri sering dianggap sebagai ukuran relatif kebaikan suatu produk yang terdiri atas kualitas desain dan kualitas kesesuaian.Masalah mutu juga saat ini sesungguhnya ialah topik yang menarik dalam pengembangan sebuah perguruan tinggi. Peningkatan mutu sebenarnya merupakan masalah yang erat kaitannya dengan kebijakan, komitmen, dan prioritas dari pengembangan lembaga pendidikan tinggi.Edward Sallis (2012: 52) memaparkan bahwa mutu ialah standar untuk menunjukkan kualitas keunggulan dari sesuatu tersebut.

Dalam kompleks mutu perguruan tinggi, mutu itu sendiri akan di anggap ketika mampu: 1) memenuhi kebutuhan masyarakat;2) 
menghadirkan tokoh yang mampu memberikan konstribusi positif bagi perkembangannya; 3) mencetak orang-orang yang dibutuhkan dalam dunia kerja; 4) melahirkan orang-orang kreatif; 5) produktif dan inovasi tinggi dalam membuka lahan pekerjaan, dan 6) melahirkan orang-orang yang profesional dalam mengembangkan ilmu pengetahuan yang dimilikinya sesuai dengan kualifikasinya (Mulyono Agus, dkk, 2007: ix).

Mutu mengandung makna derajat keungggulan suatu produk baik berupa barang maupun jasa.Oakland (1993: 5) menyatakan mutu digunakan untuk menunjukkan keunggulan dari sebuah produk atau jasa.Konsep mutu menurut Tilaar (2012: 36) bahwa mutu mempunyai banyak arti seperti: degree of action, sesuai dengan reqruirement, keseluruhan karakteristik yang memuaskan di dalam penggunaan produk. Sedangkan Rusman (2009:555) bahwa mutuadalah sesuatu yang berbeda untuk orang yang berbeda dan tergantung pada waktu dan tempat atau dikatakan sesuai dengan tujuan.Sedangkan Macdonald (1993: 6) menyatakan mutu berarti kesesuaian dengan persyaratan.Persyaratan yang memungkinkan untuk mengukur mutu dengan mengetahui bahwa sesuatu itu memenuhi syarat tertentu untuk dikatakan bermutu.

Oleh karena itu, meningkatkan mutu perguruan tinggi, ingin penulis katakan bahwa bukan suatu produk yang mudah dan dibutuhkan proses yang panjang, sebab yang utama dibutuhkan, ialah: 1) plan yang benar-benar komplit, dan 2) komitmen yang tinggi terhadap pencapaian visi, misi dan tujuan.

Ada dua hal yang menjadi alat untuk menganalisis mutu PT. Menurut Mulyono Agus, dkk (2007: 37) mutu perguruan tinggi dapat di analisis dari dua pandangan: 1) quality in fact yaitu mutu yang sesungguhnya sebagai hasil proses pembelajaran sesuai dengan kualifikasi tujuan pendidikan dan kompetensi dasar yang dimiliki para lulusan, dan 2) quality in perception, yaitu mutu lulusan yang dikuru dengan kepuasaan pelanggan dan bertambahnya minat pelanggan eksternal terhadap lulusan.

Guna mencapai hal demikian, tentu perguruan tinggi dibantu dengan beberapa lembaga internal didalam perguruan tinggi tersebut. Seperti Lembaga Penjaminan Mutu Perguruan Tinggi. Lembaga penjaminan mutu ialah lembaga yang bertugas untuk memastikan bahwa proses pembelajaran diperguruan tinggi sudah sesuai dengan visi, misi, tujuan, dan telah sesuai dengan standar yang telah disepakati dan diberlakukan (Mulyono Agus, dkk, 2007: 33).

Dari itu maka dengan adanya lembaga penjamian mutu PT, tentu evaluasi pengembangan mutu dilakukan oleh setiap perguruan tinggi dapat diukur dengan baik. Jackson (1998: 4) memberikan penekanan bahwa pelaksanaan penjaminan mutu tentu bersifat relatif dan beragam.

Konsep penjaminan mutu ialah berdasarkan tiga pandangan: 1) pada dasarnya penjaminan mutu adalah bentuk pelepasan tanggung jawab, desentralisasi tanggung jawab atas pengambilan keputusan di tingkat institusi pendidikan (Kis,2005: 5); 2) penjaminan mutu satuan pendidikan tinggi merupakan pemenuhan standar manajemen mutu pendidikan tinggi secara konsisten dan berkesinambungan (Amaripuja, 2007: 7), dan 3) secara umum tujuan penjaminan mutu pendidikan ialah untuk merencanakan, mencapai, memelihara, dan meningkatkan mutu pendidikan secara berkelanjutan pada satuan pendidikan tertentu (Rusman, 2009: 560).

Dari beberapa kombinasi pandanganyang ada, maka diperoleh benang merahnya, ialah: 1) tanggung jawab tentang mutu pendidikan tinggi sepenuhnya diserahkan kepada perguruan tinggi yang bersangkutan; 2) terdapat dua kegiatan kunci penjaminan mutu pendidikan tinggi yaitu penetapan dan pemenuhan standar manajemen mutu pendidikan tinggi; 3) mutu pendidikan tinggi harus direncanakan, dicapai, dipelihara, dan ditingkatkan secara konsisten; 
4) mutu lulusan perguruan tinggi harus memenuhi harapan seluruh stakeholders.

\subsection{Urgensi SMPI Terhadap Peningkatan Mutu Perguruan Tinggi}

Undang Undang Republik Indonesia Nomor 12 Tahun 2012 Tentang Pendidikan Tinggi pasal 53 menyatakan bahwasannya sistem penjaminan mutu internal yang dikembangkan oleh perguruan tinggi meliputi 10 standar, yaitu standar: isi, proses, kompetensi lulusan, pendidik dan tenaga kependidikan, sarana dan prasarana, pengelolaan, pembiayaan, penilaian, penelitian dan pengabdian kepada masyarakat. Menurut I Gusti Ngurah Triyana (2017: 120) menjelaskan bahwa setiap perguruan tinggi dapat mengembangkan sendiri SPMI yang sesuai dengan latar belakang sejarah, nilai dasar yang menjiwai pendirian perguruan tinggi itu, jumlah program studi dan sumber daya manusia, sarana dan prasarana perguruan tinggi tersebut tanpa campur tangan pihak lain. Lebih lanjut penjelasan dari I Gusti Ngurah Triyana (2017: 120) bahwa sekalipun setiap perguruan tinggi dapat mengembangkan SPMI secara mandiri, namun terdapat hal mendasar yang harus ada di dalam SPMI setiap perguruan tinggi. Ristekdikti menjelaskan bahwa pada dasarnya prinsip kerja SPMI mengacu pada siklus penetapan standar PT, pelaksanaan standar PT, evaluasi standar PT, pengendalian standar PT dan peningkatan standar PT (Galih Wasis Wicaksono \& Andi Al-Rizki, 2016: 1).

Oleh sebab itu, untuk menganalisis urgensi dari SPMI penulis berawal dari konsep SPMI, urgensi SPMI penulis lebih memaknainya kedalam manfaat SPMI, sebab, ada beberapa manfaat SMPI, ialah untuk penjaminan standar mutu: 1)pendidikan; 2) penelitian, dan 3) pengabdian kepada masyarakat. Ketiga konsep tersebut menarik untuk ditelusuri lebih jauh.Karena pada intinya ialah bagian yang tidak dapat dipisahkan dalam meningkatkan mutu perguruan tinggi. Untuk lebih jelasnya, penulis memaparkan secara rinci, antara lain:

\section{SPMI untuk Penjaminan Standar Mutu Pendidikan}

Standar Nasional Pendidikan yang mengacu pada PERMENRISTEKDIKTI No. 44 Tahun 2015 mencakup komponenkomponen standar: 1) kompetensi lulusan;2) isi pembelajaran; 3) proses pembelajaran;4) penilaian pembelajaran; 5) dosen dan tenaga kependidikan; 6) sarana dan prasarana pembelajaran; dan 7) pembiayaan pembelajaran.Seluruh komponen standar dalam lingkup standar mutu pendidikan harus diusahakan untuk mencapai mutu yang diinginakan baik stakeholder internal maupun eksternal. Peningkatan mutu penyelenggaraan pendidikan di perguruan tinggi dititik beratkan pada penciptaan proses pembelajaran yang aktif, efektif, efisien, dan kondusifagar dapat memberikan bekal kemampuan akademis dan profesional kepada mahasiswa, sehingga lulusan yang dihasilkan siap bersaing di pasar global (Ketut Bali Sastrawan, 2015: 1).

Upaya pencapaian mutu yang diharapkan tentu bahwasannya tidak terlepas dari dukungan kepemimpinan serta proses manajerial yang baik untuk meningkatkan etos kerja civitas akademika demi terciptanya lingkungan akademik yang kondusif. Kemampuan manajerial ialah faktor penting dan strategis dalam kerangka peningkatan mutu dan kemajuan perguruan tinggi yang dipimpinnya. Pemimpin perguruan tinggi yang bertanggung jawab harus menyadari bahwa perkembangan dan peningkatan mutu pengelolaan organisasi menjadi sangat penting.Karenaitu, untuk dapat mengungkap mengenai kinerja, hasil dan dampak perguruan tinggi secara periodik dan teratur, harus dilakukan evaluasi sebagai bagian dari pola managemen perguruan tinggi (Ernawati dan Hilwati, 200: 40).

SPMI sebagai alat untuk menjamin pencapaian mutu standar pendidikan harus 
menetapkan lingkup yang memiliki indikator mutu agar memudahkan proses pengevaluasian pada saat proses audit berlangsung. Akan tetapi indikator-indikator tersebut hanya merupakan pedoman untuk mengukur efisiensi mutu pembelajaran.Evaluasi yang baik harus dapat menjelaskan hal-hal yang diperkirakan dapat dianggap sebagai atribut mutu perguruan tinggi, yaitu: 1) relevansi tujuan dan sasaran; 2) efisiensi; 3) produktivitas; 4) efektivitas, dan 5) akuntabilitas.

Standar kompetensi lulusan perguruan tinggi meliputi kompetensi untuk seluruh mata kuliah serta pengelompokan mata kuliah, termasuk didalamnya adalah mencakup unsur sikap, pengetahuan dan keterampilan,sehingga dalam penerapannya standar kompetensi lulusan tidak terlepas dari standar isi pembelajaran. Pada ruang lingkupini, LPM melalui SPMI akan memastikan bahwa setiap program studi telah merumuskan standar kompetensi lulusan berdasarkan spesifikasi program studimelalui implementasi kurikulum yang mengacu pada KKNI serta program studi harus menciptakan atmosfir akademik yang sesuai dengan standar mutu kompetensi lulusan yang ditetapkan. Kurikulum haruslah sesuai dengan visi dan misi program studi serta mendukung visi dan misi perguruan tinggi. SPMI akan mendorong implementasi kurikulum dengan menjabarkannya melalui dokumen-dokumen kurikulum yang selalu dimutakhirkan secara periodik serta adanya kebijakan untuk meningkatkan suasana akademik yang baik melalui penyelenggaraan seminar, simposium, lokakarya sesuai dengan rumpun ilmu program studi.

Ruang lingkup standar proses pembelajaran meliputi perencanaan pembelajaraan hingga pelaporan hasil evaluasi pembelajaran. Dalam hal ini SPMI berfungsi untuk memastikan bahwa proses pembelajaran bersifat interaktif, holistik, saintifik, tematik, efektif, kolaboratif, integratif, dan kontekstual sesuai dengan KKNI dengan beban belajar mahasiswa sesuai dengan peraturan yang telah ditetapkan. Standar penilaian pembelajaran memiliki ruang lingkup penilaian dari pihak dosen dan mahasiswa, dimana hasil evaluasi oleh dosen terhadap mahasiswa akan tercantum dalam kartu hasil studi mahasiswa dan penilaian mahasiswa terhadap dosen akan dievaluasi oleh LPM yang diteruskan kepada pimpinan perguruan tinggi.

SPMI melalui proses audit internal mutu harus memastikan bahwa program studi memiliki standar penilaian, teknik dan instrumen penilaian, mekanisme dan prosedur penilaian hingga pelaporan penilaian sehingga melalui hasil audit internal mutu, standar proses ini akan terus mengalami peningkatan. Pada lingkup pendidikan tinggi, tenaga kependidikan yang memiliki kualifikasi sebagai pendidik disebut dengan dosen, sedangkan tenaga kependidikan lain disebut sebagai tenaga penunjang penyelenggaraan pendidikan. Dosen yang telah memenuhi kualifikasi akademik dan profesional akan diajukan sebagai dosen tetap, sedangkan jika dibutuhkan, program studi akan mendayagunakan dosen tidak tetap untuk memenuhi kebutuhan penjaminan mutu program akademik. Dalam hal ini, SPMI akan memastikan bahwa program studi memiliki sistem seleksi, sistem pengembangan, sistem retensi serta pemberhentian dosen dan tenaga kependidikan yang mengacu pada Permendikbud No. 49 Tahun 2014 mengenai standar dosen dan tenaga kependidikan.

Dalam rangka pemenuhan capaian pembelajaran lulusan, maka standar sarana dan prasarana memiliki peran penting untuk mendukung kebutuhan proses belajar mengajar. SPMI harus menjamin bahwa standar sarana dan prasarana yang disiapkan oleh perguruan tinggi telah sesuai dengan PERMENDIKBUD No. 49 Tahun 2014.Melalui SPMI, standar sarana dan prasarana pendidikan akan terus dievaluasi agar selalu memadai, bermutu baik, mudah diakses dan digunakan setiap saat serta selalu mengalami perkembangan untuk memenuhi kebutuhan civitas akademika. 
Standar pengelolaan pembelajaran meliputi proses perencanaan, pelaksanaan, pengendalian, pemantauan dan evaluasi serta pelaporan kegiatan belajar mengajar dalam program studi yang harus dievaluasi secara periodik melalui SPMI untuk meningkatkan mutu proses pembelajaran dan menciptakan suasana akademik yang baik. Untuk mendukung kegiatan pembelajaran perguruan tinggi, maka komponen standar pembiayaan pembelajaran harus memiliki perencanaan yang baik meliputi biaya investasi pendidikan tinggi serta biaya operasional pendidikan tinggi.SPMI harus menjamin bahwa tujuan utama rencana anggaran pendapatan dan belanjaialah untuk mengembangkan perguruan tinggi melalui implementasi tri dharma perguruan tinggi.

\section{SPMI untuk Penjaminan Standar Mutu Penelitian}

Pendidikan tinggi menyelenggarakan kegiatan penelitian dan pengabdian kepada masyarakat dengan menjunjung tinggi nilai-nilai persatuan bangsa sehingga mampu menghasilkan lulusan yang kompeten (Kadek Hengki Primayana, 2015: 13).Penelitian dalam dunia pendidikan merupakan kegiatan untuk memperoleh data untuk membuktikan suatu kebenaran atau ketidakbenaran suatu asumsi atau hipotesis menurut kaidah dan metode ilmiah yang dilakukan secara sistematis bagi kemajuan ilmu pengetahuan dan teknologi. Pada lingkup perguruan tinggi, kegiatan penelitian bertujuan untuk mengembangkan teori dan ilmu pengetahuan sehingga output dari produk penelitian dapat berupa tugas akhir, skripsi, tesis atau disertasi, publikasi ilmiah, buku ajar, produk atau paten. LPM melalui SPMI harus menjamin bahwa penelitian di perguruan tinggi memiliki standar hasil penelitian yang bermutu demi perkembangan ilmu pengetahuan dan teknologi.Penelitian harus memiliki standar isi penelitian dengan kedalaman dan keluasan materi penelitian yang memuat prinsip kemanfaatan, kemutakhiran, serta dapat menjawab kebutuhan masyarakat.

Lembaga penelitian dan pengabdian kepada masyarakat merupakan lembaga yang mewadahi bidang penelitian dan pengabdian kepada masyarakat. SPMI akan memonitoring dan mengevaluasi kesesuaian perencanaan terhadap pelaksanaan penelitian, apakah penelitian telah dilaksanakan sesuai dengan road map LP2M, serta memiliki kesesuaian antara pelaksanaan, isi, waktu, serta anggaran dana penelitian dengan proposal. Program studi harus memiliki standar peneliti dengan melihat kualifikasi akademik serta penguasaan peneliti terhadap metodologi penelitian serta menyediakan standar sarana dan prasarana penelitian yang harus memenuhi standar kenyamanan, kesehatan, serta keamanan peneliti yang harus dipastikan pengembangannya melalui SPMI.

Kegiatan penelitian program studi harus sesuai dengan rencana induk penelitian perguruan tinggi yang didukung dengan kelengkapan dokumen untuk mendukung pelaksanaan penelitian serta pengendalian mutu penelitian.Hal ini berguna sebagai indikator standar pengelolaan penelitian yang dievaluasi melalui SPMI. Perguruan tinggi wajib menyediakan dana penelitian internal bagi setiap dosen tetap untuk mengembangkan kemampuan dosen di bidang penelitian, selain itu Perguruan tinggi wajib memfasilitasi pengembangan penelitian melalui kerjasama dengan instansi di luar perguruan tinggi. L2M akan menetapkan indikator pencapaian kinerja yang akan diaudit dan dievaluasi secara periodik melalui SPMI.

\section{SPMI untuk Penjaminan Standar Mutu Pengabdian Kepada Masyarakat}

Menurut UU No 12 Tahun 2012 Pasal 47 tentang Pendidikan tinggi, pengabdian kepada masyarakat merupakan kegiatan sivitas 
akademika dalam mengamalkan ilmu pengetahuan dan teknologi untuk memajukan kesejahteraan umum dan mencerdaskan kehidupan bangsa. Di lingkup Perguruan tinggi, standar mutu pengabdian kepada masyarakat meliputi standar hasil, standar isi, standar proses, standar penialaian, standar pelaksana, standar sarana dan prasarana, standar pengelolaan, serta standar pendanaan dan pembiayaan pengabdian kepada masyarakat. Pengabdian kepada masayarakat mencakup pengembangan ilmu pengetahuan dan teknologi yang mencakup prinsip kemanfaatan, kemutakhiran serta menjawab kebutuhan masyarakat dengan hasil penelitian berupa publikasi, buku ajar atau modul pelatihan serta inovasi produk atau ilmu yang tepat guna bagi masyarakat.

Setiap kegiatan pengabdian kepada masyarakat harus terdiri atas perencanaan, pelaksanaan, dan pelaporan kegiatan pengabdian kepada masyarakat yang harus dimonitoring dan dievaluasi kesesuaiannya melalui kegiatan SPMI.Kegiatan pengabdian kepada masyarakat harus dinila mengacu pada prinsip edukatif, akuntabel, obyektif, serta transparan dimana standar penilaian pengabdian kepada masyarakat telah diatur dalam PERMENDIKBUD No 49 Tahun 2014 Pasal 58. LPM melalui SPMI harus memastikan bahwa melalui kegiatan pengabdian kepada masyarakat, akan terjadi perubahan sikap dan perubahan keterampilan dengan adanya pengetahuan baru yang disampaikan kepada masyarakat, serta kegiatan ini dapat mengatasi masalah sosial dengan memanfaatkan ilmu pengetahuan dan teknologi.

SPMI akan menjamin bahwa pihak yang terlibat dalam kegiatan pengabdian kepada masyarakat memiliki kemampuan dan keahlian sesuai dengan bidang kegiatan, serta kegiatan pengabdian kepada masyarakat memiliki tingkat kedalaman sasaran kegiatan dengan melibatkan dosen dan mahasiswa. SPMI juga akan menjamin bahwa Perguruan Tinggi akan memfasilitasi sarana dan prasarana yang memadai terkait kegiatan pengabdian kepada masyarakat dengan mempertimbangkan standar mutu keselamatan kerja, kenyamanan, serta keamanan. Idealnya, seluruh kegiatan perencanaan, pelaksanaan, pengendalian, monitoring dan evaluasi, serta pelaporan kegiatan pengabdian kepada masyarakat harus selaras dengan rencana strategis pengabdian kepada masyarakat yang dirancang oleh Perguruan Tinggi, sehingga proses ini juga tidak terlepas dari mekanisme pendanaan dan pembiayaan internal untuk kegiatan pengabdian kepada masyarakat yang diatur oleh Perguruan Tinggi. Melalui SPMI, akan dipastikan bahwa telah terjadi kesesuaian pengelolaan pendanaan untuk proses seleksi proposal, monitoring dan evaluasi, pelaporan, diseminasi hasil pengabdian kepada masyarakat, serta peningkatan kualifikasi pengabdi.

Dalam pengembangan penjaminan mutu diperlukan sikap profesional ialah mereka yangberkomitmen secara penuh tanggung jawab pada tugasnya menuju keunggulan mutu (Elton, 1995:132). Menurut Elton (1995:135) secara umum pelaksanaan penjaminan mutu dilakukan dalam tiga tahapan: a) kesepakatan tentang kebutuhan yang akan dipenuhi agar tercapai kepuasaan; b) menentukan kegiatan kegiatan yang akan dinilai kualitasnya, dan c) melakukan prosedur yang memastikan bahwa kualitas selalu terpelihara.Menurut Zaitur Rahem (2017: 117) indikator sebuah perguruan tinggi mampu memberi efek manfaat dimensional kepada lingkungan, ketika mampu menjawab masalah kontekstual yang ada.

Guna untuk menuntaskan urgensi SPMI, maka tentu harus diperkuat dengan asas yang ada di perguruan tinggi, seperti menanamkan bahwa perguruan itu sebagai:

1) Penghasil tenaga kerja yang bermutu.

Dalam pengertian ini pendidikan tinggi merupakan suatu proses dan mahasiswa dianggap sebagai output yang mempunyai nilai dalam pasaran kerja, dan keberhasilannya diukur dengan tingkat 
penghasilan yang mereka peroleh saat berkarier.

2) Lembaga pelatihan bagi karier peneliti. Mutu perguruan tinggi ditentukan oleh prestasi penelitian dosen dan mahasiswa. Jika mutu dan tanggung jawab dosen meningkat maka proses pendidikan semakin berkualitas. Jika proses pendidikan berkualitas tentu hasil pendidikan pun berkualitas. Ukuran masukan dan keluaran dihitung dengan jumlah staf yang mendapat penghargaan/ memenangkan hibah dari hasil penelitiannya, baik di tingkat nasional maupuninternasional.

3) Organisasi pengelola pendidikan yang efisien.

Dalam pengertian ini perguruan tinggi dianggap baik jika hubungannya dengan sumber daya dan dana yang tersedia, jumlah mahasiswa yang melalui proses pendidikannya semakin besar.

4) Upaya memperluas pengkayaan kehidupan.

Pertumbuhan jumlah mahasiswa dan variasi jenis progam yang ditawarkan. Rasio Dosen - Mahasiswa yang sesuai dengan regulasi, adanya pembiayaan yang tidak hanya berasal dari biaya perkuliahan, juga dipandang sebagai ukuran keberhasilan perguruan tinggi.

\section{SIMPULAN}

Kepuasan stakeholders internal merupakan salah satu indikator keberhasilan mutu perguruan tinggi. Dari uraian di atas menunjukan bahwa penerapan sistem penjaminan mutu internal di perguruan tinggi sangat penting dalam meningkatkan mutu, sehingga dapat menghasilkan lulusan yang sesuai dengan apa yang diharapkan stakeholder. Nilai penting dari sebuah upaya dari sitem penjaminan mutu internal apabila temuan yang diperoleh ditindaklanjuti oleh perencana dan pelaksana program untuk perbaikan di masa - masa yang akan datang.SPMI dibuat sebagai dasar untuk mengendalikan pengelolaan pendidikan tinggi bermutu dengan standar Nasional dan memenuhi peraturan pemerintah Republik Indonesia.Proses SPMI tidak terlepas dari kebijakan mutu, sasaran mutu penyelenggaraan pendidikan, serta seluruh dokumen mutu yang harus disosialisasikan kepada seluruh sivitas akademika dan pimpinan lembaga agar diimplementasikan secara optimal.

\section{DAFTAR PUSTAKA}

Abidin, A. A. (2017). MANAJEMEN PEMBIAYAAN PENDIDIKAN TINGGI DALAM UPAYA PENINGKATAN MUTU (Studi Kasus Pada Perguruan Tinggi Swasta Menengah di Surabaya). Jurnal Penjaminan Mutu, 3(1), 87-99.

Adina, Bloom Lewkowicz. (2007). Teaching Emotional Intelligence, Strategies and Activities for Helping Student make Effective Choices. California: Corwin Press.

Alba Cecep. (2011). Strategi Peningkatan Mutu Pendidikan Di Perguruan Tinggi.Jurnal Sosioteknologi Edisi 24 Tahun 10, h. 1184-1190.

Ernawati \& Hilwati. (2001). Pengembangan Mutu Perguruan Tinggi Dengan Pola Manajemen Terpadu.Makalah Lokakarya Asistensi Penyusunan Statuta PTS di Lingkungan Kopertis Wilayah IV, di Bandung, 25 November 2000.

Fitrah, M. (2017). Peran Kepala Sekolah dalam Meningkatkan Mutu Pendidikan. Jurnal Penjaminan Mutu, 3(1), 31-42.

Jackson, N. (1998). Understanding Standard Based Qualitative Assurance Part 2, Nuts And Bolts Of Dearing Policy Work. 
Qualitative assurance in education 6 (4).

Khoiri Muhammad. (2010).Upaya Meningkatkan Keefektifan Organisasi DalamSistem Penjaminan Mutu Perguruan TinggiDi Indonesia.Seminar Nasional VI SDM Teknologi Nuklir Yogyakarta, 18 November 2010.STTN-BATAN \& Fak. Saintek UIN SUKA

Kis, Viktoria. (2005). Quality Assurance in Tertiary Education: Current Practices in OECD Countries and a Literature Review onPotential Effects, Thematic Review of Tertiary Education. Paris: OECD.

Lewis, Elton. (1995). Quality Assurance in Teaching. Baston: Longman.

Mulyono Agus, dkk. (2007). Implementasi Sistem Manajemen Mutu UIN Maliki Malang. Malang: LPM UIN Malang.

Olssen, Mark. (2004). Education Policy: Globalization, Citizenship and Democracy. London: Sage Publications.

Primayana, K. H. (2016). MANAJEMEN SUMBER DAYA MANUSIA DALAM PENINGKATAN MUTU PENDIDIKAN DI PERGURUAN TINGGI. Jurnal Penjaminan Mutu, 1(2), 7-15.

Punang Amaripuja. (2007). Penjaminan Mutu Pendidikan Tinggi di Indonesia. Yogyakarta: Universitas Muhammadiyah Yogyakarta.

Ratnawatie Kresma (1998). Birokrasi Perguruan Tinggi Di Indonesia.Pusat Kajian Hukum dan Pembangunan, Perspektif Volume 3, Nomor 2, Edisi April.

RISTEKDIKTI (2010). Sistem Penjaminan Mutu Perguruan Tinggi. Jakarta: Direktorat Jenderal Pendidikan Tinggi.
RISTEKDIKTI (2016). Sistem Penjaminan Mutu Perguruan Tinggi. Jakarta: Direktorat Jenderal Pendidikan Tinggi.

Rusman.(2009). Manajemen Kurikulum, Seri Manajemen Sekolah Bermutu. Jakarta: Raja Grafindo Persada.

Sallis Edward. (2012). Total Quality Management In Education: Manajemen Mutu Pendidikan. Yogjakarta: Ircisod.

Sastrawan, K. B. (2016). Profesionalisme Guru Dalam Upaya Meningkatkan Mutu Pembelajaran. Jurnal Penjaminan Mutu, 2(2), 65-73.

Soehendro Bambang. (1996). Kerangka Pengembangan Pendidikan Tinggi Jangka Panjang 1996 - 2005. Jakarta: Departemen Pendidikan dan Kebudayaan RI.

Siram Reddy. (2015). Manajemen Penjaminan Mutu Layanan Akademik Perguruan Tinggi. Jurnal Ilmu Pendidikan, Jilid 21, Nomor 1, h. 54-58.

Sufyarma.(2004). Kapita Selekta Manajemen Pendidikan.Bandung: Alfabeta.

Tilaar, H.A.R. (2012). Standar Pendidikan Nasional, Suatu Tinjauan Kritis. Jakarta: Rineka Cipta.

Tsui, C. Cecelia. (2002). Quality in Higher Education: Policies and Practices.A Hongkong Perspective Introduction and research Approach. Dissertation.

Triyana, I. G. N. (2017). PENJAMINAN MUTU PENDIDIKAN MELALUI TEKNOLOGI INFORMASI DI INSTITUT HINDU DHARMA NEGERI DENPASAR. Jurnal Penjaminan Mutu, 3(1), 119-126.

Willar Debby,. Dkk. (2015). Identifikasi Profil Budaya Organisasi Yang Mendukung ImplementasiSistem Penjaminan Mutu 
Perguruan Tinggi. Cakrawala Pendidikan, Juni 2015, Th. XXXIV, No. 2, h. 192-202.

Wicaksono Galih Wasis\& Al-Rizki Andi.(2016). Peningkatan Kualitas Evaluasi Mutu Akademik Universitas Muhammadiyah Malang melalui Sistem Informasi Mutu.Kinetik, Vol.1, No.1, hal. $1-8$.
Rahem, Z. (2017). Kontribusi-Dimensional Perguruan Tinggi Swasta Terhadap Bangunan Sosial dan Budaya Masyarakat Madura (Studi atas Kiprah Perguruan Tinggi Swasta di Kabupaten Sumenep Madura). Jurnal Penjaminan Mutu, 3(1), 111-118. 